Article

\title{
The Anti-Wrinkle Mechanism of Melatonin in UVB Treated HaCaT Keratinocytes and Hairless Mice via Inhibition of ROS and Sonic Hedgehog Mediated Inflammatory Proteins
}

\author{
Eun Kyung Park ${ }^{\dagger}$, Hyo-Jung Lee ${ }^{\dagger}$, Hyemin Lee ${ }^{\circledR}$, Ju-Ha Kim, Jisung Hwang, Ja Il Koo and \\ Sung-Hoon Kim * (iD) \\ College of Korean Medicine, Kyung Hee University, Seoul 02447, Korea; friendly124@hanmail.net (E.K.P.); \\ hyonice77@naver.com (H.-J.L.); glansy555@gmail.com (H.L.); 964juha@hanmail.net (J.-H.K.); \\ hjsung0103@naver.com (J.H.); freelink78@naver.com (J.I.K.) \\ * Correspondence: sungkim7@khu.ac.kr; Tel.: +82-2-961-9233 \\ + These authors contributed equally to this work.
}

Received: 17 May 2018; Accepted: 6 July 2018; Published: 8 July 2018

\begin{abstract}
Though melatonin is known to improve ultraviolet B (UVB)-induced oxidative damage and inflammatory conditions via the blockade of the nuclear factor (NF)- $\mathrm{kB}$, interleukin (IL)-6, there is no report on the anti-wrinkle effect of melatonin to date. Hence in the present study, the anti-wrinkle mechanism of melatonin was elucidated in UVB treated HaCaT keratinocytes and hairless mice. Herein melatonin protected against a radical initiator tert-Butyl hydroperoxide $(\mathrm{t}-\mathrm{BOOH})$ induced reactive oxygen species (ROS) production, matrix metalloprotease 1 (MMP-1), pro-collagen and cytotoxicity in $\mathrm{HaCaT}$ keratinocytes. Additionally, melatonin suppressed the expression of sonic hedgehog (SHH) and GLI1 for hedgehog signaling and p-NF- $\mathrm{kB}$, cyclooxygenase (COX-2), phospho-extracellular signal-regulated kinase-1 (p-ERK) for inflammatory responses in UVB treated HaCaT keratinocytes. Furthermore, melatonin protected skin from wrinkle formation, transdermal water loss in hairless mice irradiated by UVB for 8 weeks. Notably, melatonin prevented against epidermal thickness and dermal collagen degradation in UVB irradiated hairless mice by Hematoxylin and Eosin and Masson's trichrome staining. Taken together, these findings suggest that melatonin reduces wrinkle formation via inhibition of ROS/SHH and inflammatory proteins such as NF-kB/COX-2/ERK/MMP1.
\end{abstract}

Keywords: melatonin; UVB; HaCaT keratinocytes; collagen; ROS; hedgehog; Cox-2; MMP-1

\section{Introduction}

Facial wrinkles are known as one of the most prominent features for skin aging [1]. Skin aging is usually classified as either intrinsic (chronological) and extrinsic (photoaging) aging. Extrinsic aging shows photoaged skin with rough wrinkles mainly due to exposure to sunlight including ultraviolet $B$, while intrinsic aging is induced by aging genetic factors with a pale and smooth wrinkle formation [2]. It is well documented that the loss of skin elasticity and degradation of elastic fibers and collagen are usually shown in aged or wrinkled skin [3,4]. Previous evidence reveals that reactive oxygen species (ROS) in dermal fibroblast and epidermal keratinocyte produce matrix metalloproteinases (MMPs) to induce collagen degradation leading to skin aging, since MMPs degrade the extracellular matrix, including collagen fibers and thus contributes to wrinkle formation [5]. Marked loss of fibrillin-positive structures such as collagen type IV, VII and XVII in dermal and epidermal junctions contribute to wrinkles by weakening the bond between the dermis and epidermis [6,7]. In particular, UVB exposure upregulates the expression of MMP-1, -3 and -9 as well as sonic hedgehog (SHH) and GLI1 [8,9] in 
the human epidermis to induce wrinkle formation. Thus, recently many phytochemicals such as magnolo 1 [10], abietic acid [11], Galla Chinensis extract [12] and green tea polyphenols [13] were reported to block skin damage due to chronic UVB irradiation. Additionally, melatonin was reported to protect human keratinocytes from UVB-induced oxidative stress and DNA damage. Nevertheless, the anti-wrinkle mechanism of melatonin still remains unclear to date. Thus, in the present study, the anti-wrinkle molecular mechanism of melatonin was investigated in $\mathrm{t}-\mathrm{BOOH}$ or UVB treated human keratinocytes and UVB irradiated SKH-1 hairless mice.

\section{Results}

\subsection{Melatonin Protected Against t-BOOH Induced ROS Production and Cytotoxicity in HaCaT Keratinocytes}

It is well known that tert-Butyl hydroperoxide ( $\mathrm{t}-\mathrm{BOOH})$ has been used as a radical polymerization initiator to induce cell damage [14]. To find out the protective effect of melatonin (Figure 1a) in t-BOOH induced cytotoxicity in HaCaT keratinocytes, an MTT assay was conducted. As shown in Figure 1b,c, $\mathrm{t}$-BOOH or UVB $\left(30 \mathrm{~mJ} / \mathrm{cm}^{2}\right)$ exerted cytotoxicity better than melatonin in HaCaT keratinocytes. However, melatonin significantly suppressed the $\mathrm{t}-\mathrm{BOOH}$ induced cytotoxicity (Figure 2a) and ROS production at the concentrations of 1 and $2 \mathrm{mM}$ in HaCaT keratinocytes (Figure 2b).

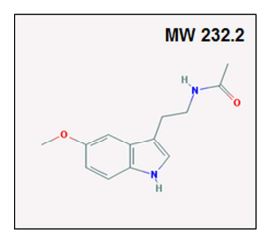

(a)

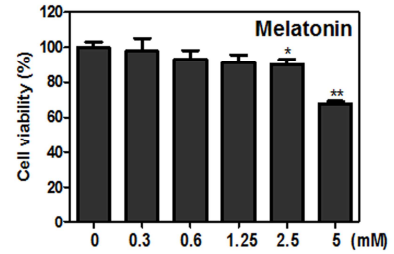

(b)
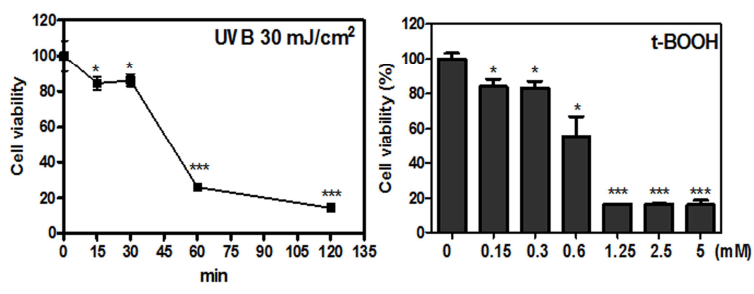

(c)

Figure 1. The effect of Melatonin, $\mathrm{t}-\mathrm{BOOH}$ and UVB on the cytotoxicity in HaCaT cells. (a) Chemical structure of melatonin. Molecular weight $=232.2(\mathbf{b}, \mathbf{c})$ HaCaT cells were seeded onto 96-well microplates at a density of $1 \times 10^{4}$ cells/well and treated with various concentrations of Melatonin $(0,0.3,0.6,1.25$, 2.5 or $5 \mathrm{mM})$ or $\mathrm{t}-\mathrm{BOOH}(0,0.15,0.3,0.6,1.25,2.5$ or $5 \mathrm{mM})$ for $24 \mathrm{~h}$. HaCaT cells were exposed to UVB $\left(30 \mathrm{~mJ} / \mathrm{cm}^{2}\right)$ for $15 \mathrm{~min}, 30 \mathrm{~min}, 60 \mathrm{~min}$ or $120 \mathrm{~min}$. Data represent means $\pm \mathrm{SD} .{ }^{*} p<0.05,{ }^{* *} p<0.01$ and ${ }^{* * *} p<0.001$ versus untreated control.

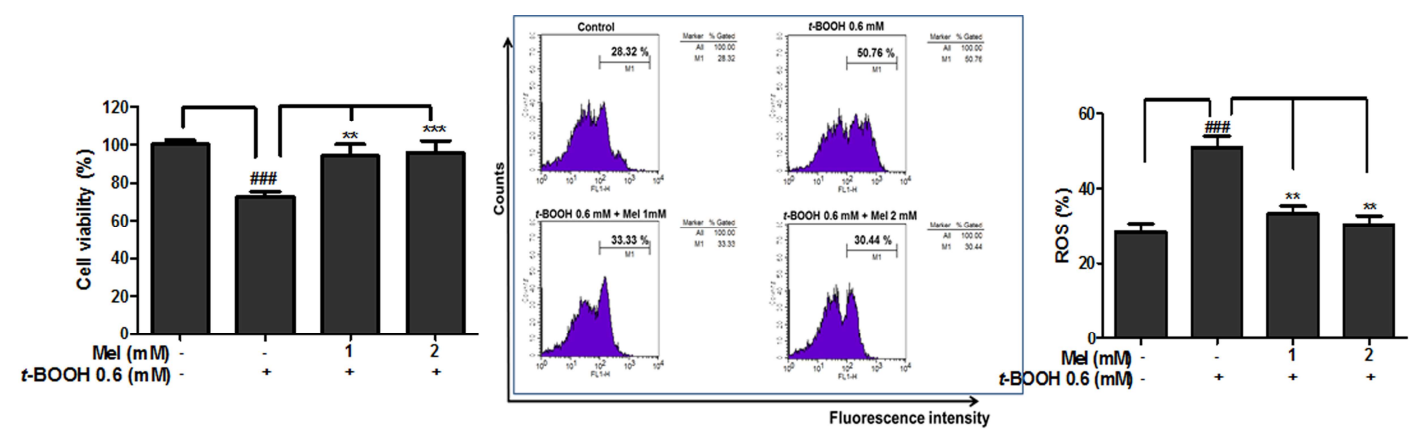

(a)

(b)

Figure 2. Melatonin suppressed t-BOOH induced cytotoxicity and ROS production in HaCaT keratinocytes. (a) Cells were pretreated with melatonin for $24 \mathrm{~h}$ and then with t-BOOH $(0.6 \mathrm{mM})$ for $6 \mathrm{~h}$. (b) ROS generation (\%) was measured using ROS-sensitive fluorometric probe 2,7-dichlorofluorescein diacetate (DCFDA) by flow cytometric analysis. Data represent means \pm SD. ${ }^{* * *} p<0.001$ and ${ }^{* *} p<0.01$ versus t-BOOH control, \#\#\# $p<0.001$ versus normal control. 
2.2. Melatonin Attenuated the mRNA Expression of MMP-1, Pro-Collagen Degradation in $t-B O O H$ or UVB Induced HaCaT Keratinocytes

There is accumulating evidence that the expression of MMPs was upregulated in t-BOOH induced $\mathrm{HaCaT}$ keratinocytes [11,15]. Additionally, UVB-induced photoaging is known to be mediated by increased expression of MMP-1 and collagen degradation $[16,17]$. To determine the effects of $\mathrm{t}-\mathrm{BOOH}$ or UVB on MMP-1 expression, a qRT-PCR assay was performed. As shown in Figure 3a, melatonin reduced the mRNA expression of MMP- 1 and increased the expression of pro-collagen in t-BOOH treated $\mathrm{HaCaT}$ keratinocytes. Additionally, melatonin suppressed the mRNA expression of MMP-1 and increased the expression of pro-collagen in UVB treated HaCaT keratinocytes (Figure 3b). Additionally, melatonin increased the expression of collagen XVII in UVB treated HaCaT keratinocytes (Figure 3c).

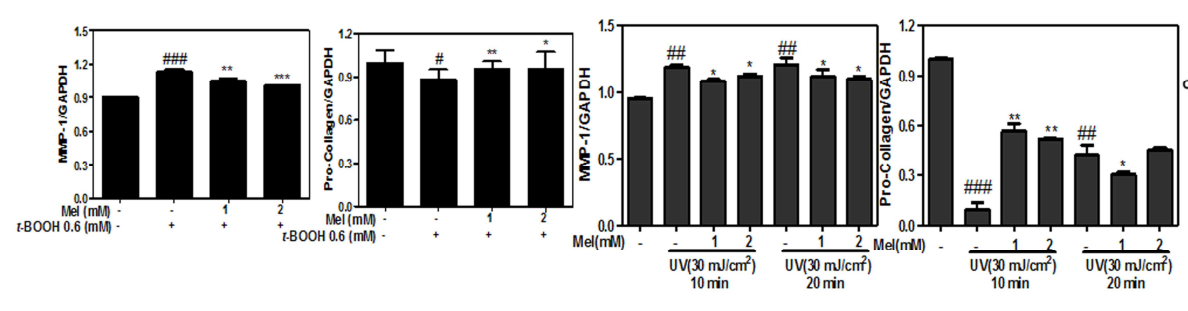

(a) (b)

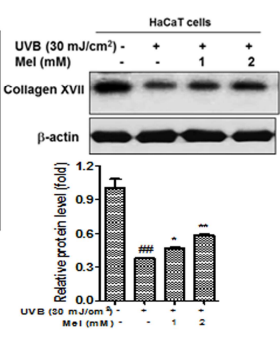

(c)

Figure 3. The melatonin attenuated the mRNA expression of MMP-1 and pro-collagen in $\mathrm{t}-\mathrm{BOOH}$ or UVB induced HaCaT keratinocytes. (a) Cells were pretreated with melatonin for $24 \mathrm{~h}$ and then with t-BOOH $(0.6 \mathrm{mM})$ for $6 \mathrm{~h}$. mRNA expressions of MMP-1 and pro-collagen were analyzed by Real-Time PCR. Data represent means \pm SD. ${ }^{* * *} p<0.001,{ }^{* *} p<0.01$ and ${ }^{*} p<0.05$ versus t-BOOH control, \#\#\# $p<0.001$ versus normal control. (b) Cells were pretreated with melatonin for $24 \mathrm{~h}$ and then irradiated by UVB $\left(30 \mathrm{~mJ} / \mathrm{cm}^{2}\right)$ for $10 \mathrm{~min}$ or $20 \mathrm{~min}$. mRNA expressions of MMP-1 and pro-collagen were analyzed by Real-Time PCR. Data represent means \pm SD. ${ }^{* *} p<0.01$ and ${ }^{*} p<0.05$ versus UVB control, \#\#\# $p<0.001$ and \#\# $p<0.01$ versus normal control. (c) HaCaT cells were exposed to UVB $\left(30 \mathrm{~mJ} / \mathrm{cm}^{2}\right)$ for $10 \mathrm{~min}$ and subjected to Western blotting for collagen XVII and $\beta$-actin. Graphs represent quantitative data of protein expression adjusted by $\beta$-actin. Data represent means \pm SD. ** $p<0.01$ and * $p<0.05$ versus UVB control, \#\# $p<0.01$ versus normal control.

\subsection{Melatonin Effectively Suppressed the UVB-Induced Hedgehog Signaling and MMP-1 Related Proteins in HaCaT Keratinocytes}

To determine whether melatonin inhibits UVB-induced MMP-1(photoaging marker) related proteins, Western blotting was performed. After the exposure to UVB $30 \mathrm{~mJ} / \mathrm{cm}^{2}$ for $10 \mathrm{~min}$ or 20 min, MMP-1 related proteins (p-ERK, pp-38, COX-2 and MMP-1) were significantly affected at UVB $30 \mathrm{~mJ} / \mathrm{cm}^{2}$ for $10 \mathrm{~min}$ (Figure $4 \mathrm{a}$ ). To determine the molecular mechanism of melatonin, we examined the effects of melatonin on the hedgehog signaling pathway, since hedgehog signaling (SHH/GLI1) plays a key role in inducing MMP-1 [18]. Consistently, melatonin reduced the expression of UVB-induced SHH and GLI1 at 1 and $2 \mathrm{mM}$ (Figure 4b). Additionally, melatonin reduced the expression of p-NF- $\mathrm{kB}, \mathrm{p}-\mathrm{ERK}$ and COX-2 in the UVB-treated HaCaT keratinocytes, while the phosphorylation of NF- $\mathrm{KB}$, ERK and COX-2 was increased by UVB irradiation (Figure $4 \mathrm{~b}$ ). Furthermore, melatonin suppressed the expression of MMP-1 in t-BOOH or UVB treated HaCaT keratinocytes (Figure 4c). 


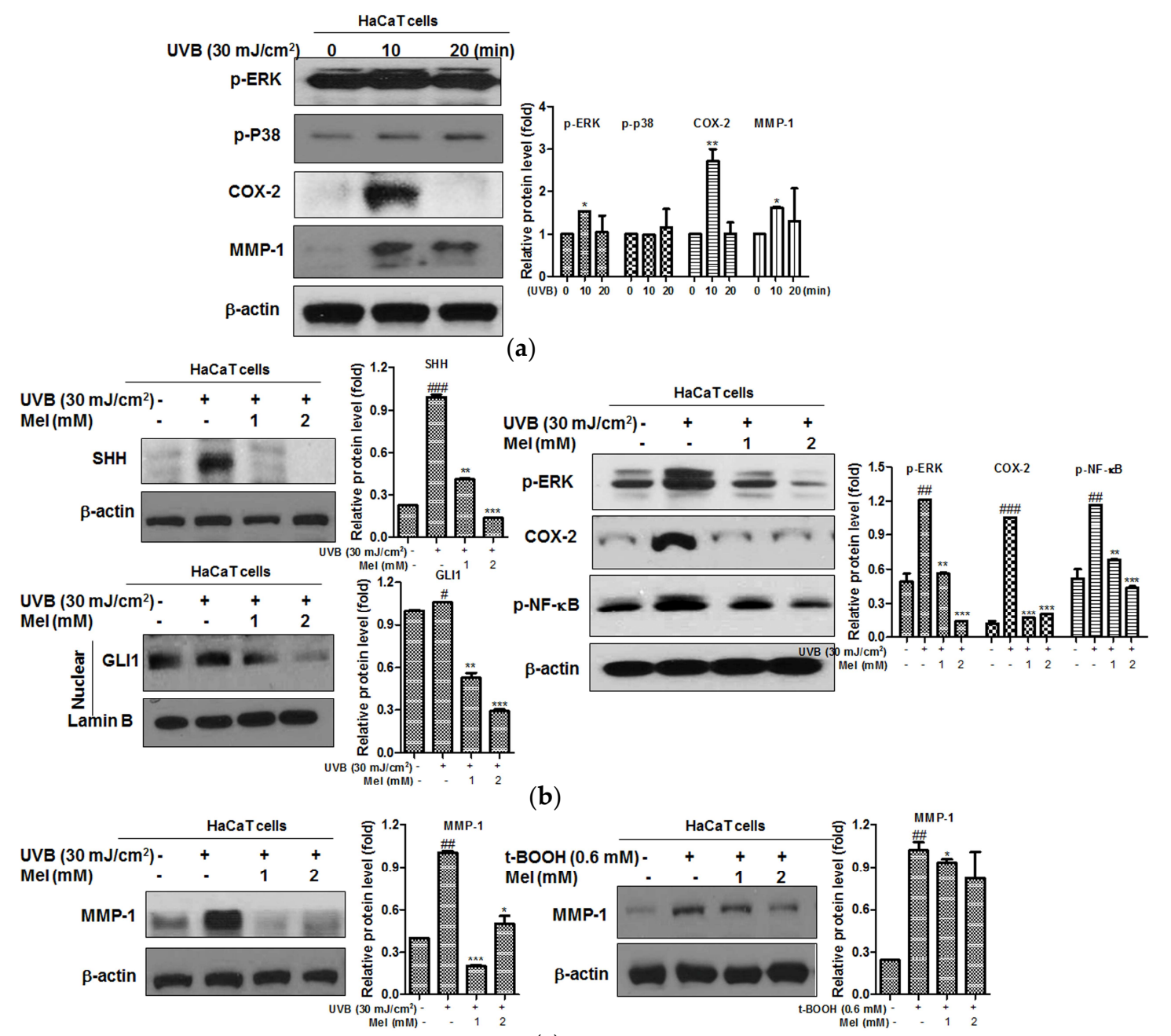

(c)

Figure 4. The melatonin attenuated the expression of SHH, GLI1 and MMP-1 related proteins in t-BOOH or UVB treated HaCaT keratinocytes. (a) HaCaT cells were exposed to UVB $\left(30 \mathrm{~mJ} / \mathrm{cm}^{2}\right)$ for $10 \mathrm{~min}$ or $20 \mathrm{~min}$ and subjected to Western blotting for p-ERK, PP38, COX-2, MMP-1 and $\beta$-actin. (b), (c) Cells were pretreated with melatonin for $24 \mathrm{~h}$, irradiated with UVB $\left(30 \mathrm{~mJ} / \mathrm{cm}^{2}\right)$ for $10 \mathrm{~min}$ and then subjected to Western blotting for SHH, GLI1 (nuclear fraction), p-ERK, COX-2, p-NF-kB, MMP-1, $\beta$-actin and Lamin B. Cells were pretreated with melatonin for $24 \mathrm{~h}$ and then with $\mathrm{t}-\mathrm{BOOH}(0.6 \mathrm{mM})$ for $6 \mathrm{~h}$. Graphs represent quantitative analysis of protein expression adjusted by $\beta$-actin. Data represent

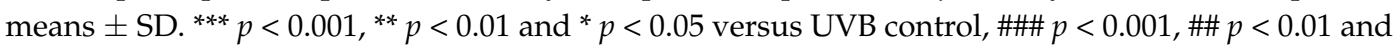
$\# p<0.05$ versus normal control.

\subsection{Melatonin Prevented Against Loss of Water on the Dorsal skin of SKH1 Hairless Mice Exposed to UVB}

It is well known that UVB can induce skin damages such as melanogenesis, erythema and epidermal thickness in the epidermis, leading to wrinkle formation in the dermis [19]. As shown in Figure 5a, melatonin significantly reduced the loss of water on the dorsal skin of SKH-1 hairless mice 8 weeks after UVB treatments, while the loss of water was accentuated in the UVB alone treated control compared to untreated normal control. 


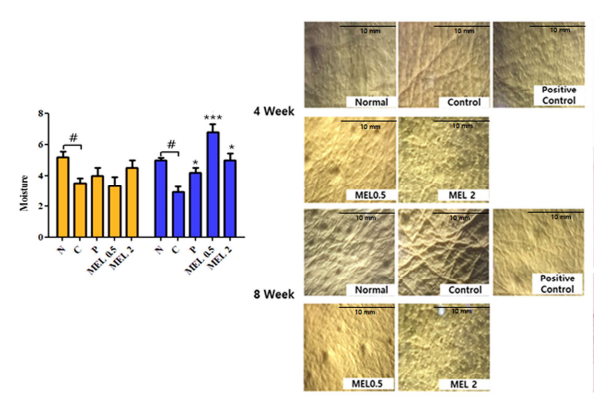

(a)

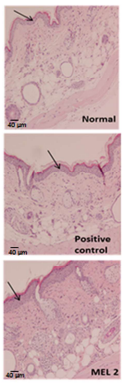

(b)

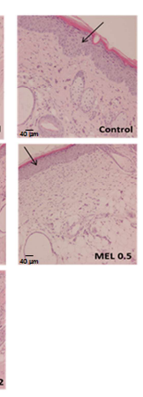

(c)
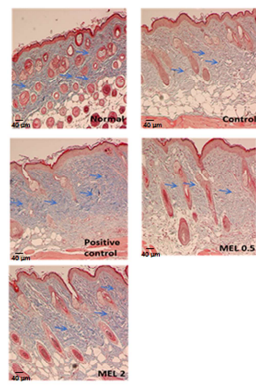

(d)

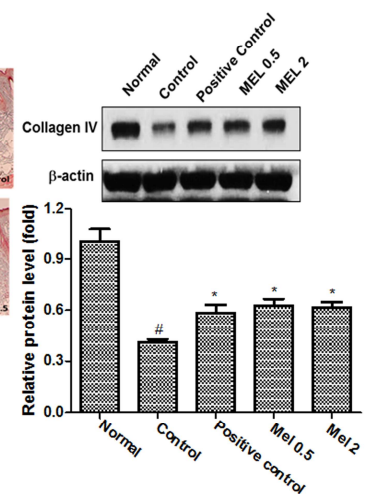

(e)

Figure 5. The melatonin significantly suppresses wrinkles and collagen fibers in the dorsal skin of SKH 1 hairless mice. N, Normal; C, Control + UVB irradiation; P, Positive control: Retinoic acid $2 \mathrm{mg} / \mathrm{kg}+$ UVB; MEL 0.5, Melatonin $0.5 \mathrm{mg} / \mathrm{kg}+\mathrm{UVB}$; MEL 2, Melatonin $2 \mathrm{mg} / \mathrm{kg}+$ UVB. (a) Effect of melatonin on water loss in the dorsal skin of SKH 1 hairless mice. Data represent means \pm SD. ${ }^{* * *} p<0.001$ and * $p<0.05$ versus UVB Control, \# $p<0.05$ versus Normal control. (b) Effect of melatonin on wrinkles in the dorsal skin of SKH 1 hairless mice. Melatonin reduced the degree of wrinkles induced by UVB irradiation on the dorsal skin of SKH1 hairless mice. Images of skin replicas were casted on the dorsal skin surface of mice using SILFLO. Scale bars $=10 \mathrm{~mm}$ (c) Hairless mouse skin was stained with hematoxylin and eosin $(\times 100)$. Epidermis thickness was measured under light microscopy. Black arrow (epidermis). Scale bars $=40 \mu \mathrm{m}$ (d) Collagen fiber formation was evaluated using Masson's trichrome staining. Collagen fiber bundles are shown in blue area (Blue arrow) $(\times 100)$ Scale bars $=$ $40 \mu \mathrm{m}$. (e) Effect of melatonin on collagen IV expression in UVB-exposed mice skin tissues. Skin tissues were homogenized on ice and the extracts were subjected to Western blotting. Graphs represent the quantitative analysis of protein expression adjusted by $\beta$-actin. Data represent means \pm SD. ${ }^{*} p<0.05$ versus UVB control, \# $p<0.05$ versus normal control.

2.5. Melatonin Suppressed the Degree of Wrinkles and Epidermal Thickness Induced by UVB Irradiation on the Dorsal skin of SKH1 Hairless Mice

The degrees of wrinkles were observed on the dorsal skin of UVB irradiated SKH-1 hairless mice by SILFLO casting method, while those were reduced in melatonin- treated SKH-1 hairless mice under UVB exposure are shown in Figure 5b. Consistently, melatonin treatment reduced epidermal thickness induced by UVB irradiation by H\&E staining and Masson's trichrome staining revealed that melatonin treatment maintained the blue color for collagen staining compared to the UVB- alone- treated control in the dermis of the skin of UVB irradiated SKH-1 hairless mice as shown in Figure 5c,d. Consistently, as shown in Figure 5e, melatonin significantly blocked the degradation of collagen IV in skin tissues of SKH-1 hairless mice exposed to UVB irradiation.

\section{Discussion}

Melatonin (N-acetyl-5-methoxytryptamine) is known to have multi-biological activities to regulate circadian rhythms [20] and to work as a hormone or neurotransmitter [21], and as an anti-inflammatory [22,23] and antioxidant [24] agent. Especially, melatonin suppressed the ROS production in rat lens [25] and IL-3 stimulated leukocytes [24] and also enhanced the survival of UVB treated keratinocytes by suppressing apoptosis [26].

Herein, the anti-wrinkle mechanism of melatonin was elucidated in $\mathrm{t}-\mathrm{BOOH}$ or UVB treated HaCaT keratinocytes and UVB treated hairless mice.

Melatonin suppressed the ROS production and cytotoxicity in free radical initiator t-BOOH treated $\mathrm{HaCaT}$ keratinocytes, implying that melatonin protects $\mathrm{HaCaT}$ keratinocytes from $\mathrm{t}-\mathrm{BOOH}$ induced cytotoxicity, since ROS play a pivotal role in skin damage by UVB-irradiation. 
UVB-induced photoaging is initiated by the production of ROS [27,28], which activate several receptors for IL-1, keratinocyte growth factor and tumor necrosis factor (TNF)- $\alpha[29,30]$. Activation of these receptors induces downstream signaling pathways of mitogen-activated protein kinases (MAPKs) such as p38, JNK and ERK, which lead to an increase of the nuclear transcription such as NF- $\mathrm{kB}$ and AP-1 $[29,31,32]$. Additionally, the activation of the transcription factor NF- $k B$ induces the expression of inflammatory cytokines such as COX-2, IL-6 and MMPs [33,34]. Continuous UVB exposure induces expression of MMPs, which degrades collagen by collagen breakdown as well as by the inhibition of procollagen synthesis $[35,36]$. Interestingly, melatonin suppressed the expression of COX-2, p-ERK, p-NF- $\mathrm{KB}$ and MMP-1 and increased the expression of procollagen and collagen XVII in UVB induced $\mathrm{HaCaT}$ cells, indicating that melatonin inhibits inflammatory cytokines and photoaging markers, leading to an anti-wrinkle effect in the skin.

The accumulating evidence reveals that the Hedgehog $(\mathrm{Hh})$ signaling pathway regulates normal growth but its abnormal activation can promote cancer progression and epidermal development $[8,9,37,38]$. Therefore, to identify the molecular mechanism associated with UVB-induced photoaging, the role of $\mathrm{Hh}$ signaling was evaluated in UVB treated HaCaT cells. Here, melatonin reduced the expression of UVB-induced $\mathrm{SHH}$ as a Hh ligand and GLI1 as a transcriptional effector of Hh pathway, demonstrating that melatonin exerts an anti-photoaging effect via the inhibited $\mathrm{Hh}$ signaling pathway.

It is well documented that UVB induces skin damages leading to wrinkle formation due to collagen degradation in the dermis $[39,40]$. Here, melatonin protected skin from wrinkle formation, transdermal water loss in UVB treated hairless mice comparable to positive control retinoic acid, indicating that melatonin works against wrinkle formation in the dermis possibly via inhibition of collagen degradation. Consistently, Masson's trichrome staining revealed that melatonin treatment maintained the blue color staining for collagen and reduced the epidermal thickness compared to the UVB- alone-treated group in the dermis of the skin of UVB irradiated SKH-1 hairless mice, implying a protective effect of melatonin on wrinkle formation by collagen degradation.

Collectively, melatonin suppressed ROS production and the expression of MMP-1 in $\mathrm{t}-\mathrm{BOOH}$-induced $\mathrm{HaCaT}$ keratinocytes. Additionally, melatonin suppressed the expression of UVB-induced MMP-1 and MMP-1 related proteins (inflammatory proteins), increased procollagen in $\mathrm{HaCaT}$ keratinocytes and reduced the expression of hedgehog signaling proteins and protected against epidermal thickness, transdermal water loss, collagen degradation and wrinkle formation on the dorsal skin of UVB treated hairless mice. Overall, these findings demonstrate that melatonin protects against UVB induced oxidative skin damage including wrinkle formation via the inhibition of ROS, MMP-1 and the hedgehog signaling pathway.

\section{Materials and Methods}

\subsection{Chemicals}

Melatonin (N-acetyl-5-methoxytryptamine) (M5250) was purchased from Sigma (St. Louis, MO, USA).

\subsection{Cell Culture}

Human skin keratinocyte cell line HaCaT cells (CRL-2404) were bought from American Type Culture Collection (ATCC). The cells were grown in Dulbecco Modified Eagle Medium (DMEM) (Gibco, Grand Island, NY, USA) with 10\% fetal bovine serum, antimycotic (amphotericin B $0.25 \mu \mathrm{g} / \mathrm{mL}$ ) and antibiotics (penicillin, $100 \mathrm{U} / \mathrm{mL}$; streptomycin, $100 \mu \mathrm{g} / \mathrm{mL}$ ). 


\subsection{UVB Irradiation}

HaCaT cells were treated with melatonin $(0,1$ or $2 \mathrm{mM})$ for $24 \mathrm{~h}$. After washing with phosphate-buffered saline (PBS), the cells were irradiated with $30 \mathrm{~mJ} / \mathrm{cm}^{2}$ of UVB $(312 \mathrm{~nm})$ for 10 min using the CL-1000 Ultraviolet Crosslinker (Ultra-violet products Ltd, Cambridge, UK).

\subsection{Cell Viability Assay}

The cytotoxic effect of melatonin was assessed by using a 3-(4,5-dimethylthiazol-2-yl)2,5-diphenyltetrazolium bromide (MTT) assay. In brief, HaCaT cells $\left(1 \times 10^{4}\right.$ cells/well) were seeded onto 96-well culture plates and treated to various concentrations of melatonin for $24 \mathrm{~h}$. The cells were incubated with MTT $(1 \mathrm{mg} / \mathrm{mL}$ ) (Sigma Chemical, St. Louis, MO, USA) for $2 \mathrm{~h}$ and the formazan crystals were dissolved in DMSO. The Optical density (OD) was measured by using a microplate reader (Molecular Devices Co., CA, USA) at $570 \mathrm{~nm}$ wavelength. Cell viability was calculated as a percentage of viable cells in melatonin-treated group versus untreated control.

\subsection{RT-qPCR Assay}

RT-qPCR was performed with the LightCycler TM instrument (Roche Applied Sciences, Indianapolis, IN, USA) with the following primers, human MMP-1 forward: $5^{\prime}$-CATGACTTTCC TGGAATTGG-3'; reverse-5'-CCTGCAGTTGAACCAGCTAT-3' (Bioneer, Daejeon, Korea), human pro-collagen forward: 5'-CAGGCAAACCTGGTGAACA-3'; reverse-5'-CTCGCCAGGGAAACCT CT-3', human GAPDH-forward: 5'-GCACCGTCAAGGCTCTAGAAC-3'; reverse-5'-GGATCTCGCTC CTGGAAGAT-3' (Bioneer, Daejeon, Korea).

\subsection{Western Blotting}

$\mathrm{HaCaT}$ Cells were pretreated with melatonin for $24 \mathrm{~h}$, then with t-BOOH $(0.6 \mathrm{mM})$ and exposed to UVB irradiation $\left(30 \mathrm{~mJ} / \mathrm{cm}^{2}\right)$ were lysed in lysis solution $(50 \mathrm{mM}$ Tris- $\mathrm{HCl}, \mathrm{pH} 7.4,150 \mathrm{mM}$ $\mathrm{NaCl}, 1 \mathrm{mM}$ EDTA, $1 \mathrm{mM} \mathrm{Na} \mathrm{VO}_{4}, 1 \%$ Triton X-100, $0.1 \%$ SDS, $1 \mathrm{mM} \mathrm{NaF}$ and $1 \times$ protease inhibitor cocktail) on ice and spun down at $14,000 \times g$ for $20 \mathrm{~min}$ at $4{ }^{\circ} \mathrm{C}$. The supernatants were collected and quantified for protein concentration by using an RC DC protein assay kit (Bio-Rad, Hercules, CA, USA), The proteins samples were separated on 4-12\% NuPAGE Bis-Tris gels (Novex, Carlsbad, CA, USA) and transferred to a Hybond ECL transfer membrane for detection with antibodies for p-ERK, pp-38, COX-2, MMP-1, SHH and GLI1 (Cell Signaling Technology, Beverly, MA, USA), Collagen IV, Collagen XVII (Abcam, Cambridge, UK), Lamin B (Santa Cruz Biotechnologies, Santa Cruz, CA, USA) and $\beta$-actin (Sigma, St. Louis, MO, USA).

\subsection{Nuclear Fraction for GLI1}

$\mathrm{HaCaT}$ cells were pretreated with melatonin for $24 \mathrm{~h}$ and then exposed to UVB irradiation $\left(30 \mathrm{~mJ} / \mathrm{cm}^{2}\right)$. Then nuclear fraction of the cells was prepared using NE-PER nuclear and cytoplasmic extraction reagents (Thermo, Rockford, IL, USA) based on the manufacturer's protocol for Western blotting with the GLI1 antibody.

\subsection{Measurement of Reactive Oxygen Species (ROS) Generation}

The compound 2,7-Dichlorofluorescein diacetate (DCFH-DA) was used to measure the level of ROS production. HaCaT cells were pretreated with melatonin for $24 \mathrm{~h}$, with t-BOOH $(0.6 \mathrm{mM})$ for $6 \mathrm{~h}$ and then exposed to $5 \mu \mathrm{M}$ DCFH-DA for $30 \mathrm{~min}$ at $37^{\circ} \mathrm{C}$. Fluorescence intensity was measured by FACSCalibur (Becton Dickinson, Franklin Lakes, NJ, USA).

\subsection{Animals and Treatments}

Fifty female SKH-1 mice (6-week-old) were purchased from Samtako Biokorea (Samtako Biokorea, Osan, Kyunggido, Korea) and housed at IK Science cage under consistent condition (temperature: 
$22 \pm 1{ }^{\circ} \mathrm{C}$, humidity: $55 \pm 3 \%, 12 \mathrm{~h}$ light/ dark cycles). All experiments were performed in accordance with the guidelines established by Kyung Hee University. Mice were acclimated for one week and randomly divided into five groups $(n=10)$ during the experimental period: the normal group $(\mathrm{N})$, control group (only UVB treated group; three times a week by UV-1000 group (Dongseo Science, Dangjin, Korea), positive control retinoic acid (Sigma Aldrich, USA) group (2 mg/kg) (B), melatonin $0.5 \mathrm{mg} / \mathrm{kg}$ group (MEL 0.5) and the melatonin $1 \mathrm{mg} / \mathrm{kg}$ group (MEL 1). Melatonin was orally administered to the mice of each group daily for 8 weeks, while saline was administered to the normal and control groups and retinoic acid was i.p injected in the positive control group three times a week for 8 weeks.

UVB irradiation schedule is as follows (Figure 6):

(1) 0 week: $60 \mathrm{~mJ} / \mathrm{cm}^{2}$ for $200 \mathrm{~s}$, three times a week (1 minimal erythema dose; M.E.D)

(2) 1 week: $120 \mathrm{~mJ} / \mathrm{cm}^{2}$ for $400 \mathrm{~s}$, three times a week (2 M.E.D)

(3) 2 3 weeks: $180 \mathrm{~mJ} / \mathrm{cm}^{2}$ for $600 \mathrm{~s} 1$ week: $120 \mathrm{~mJ} / \mathrm{cm}^{2}$ for $400 \mathrm{~s}$, three times a week (3 M.E.D)

(4) 4 5 weeks: $240 \mathrm{~mJ} / \mathrm{cm}^{2}$ for $800 \mathrm{~s}$, three times a week (4 M.E.D)

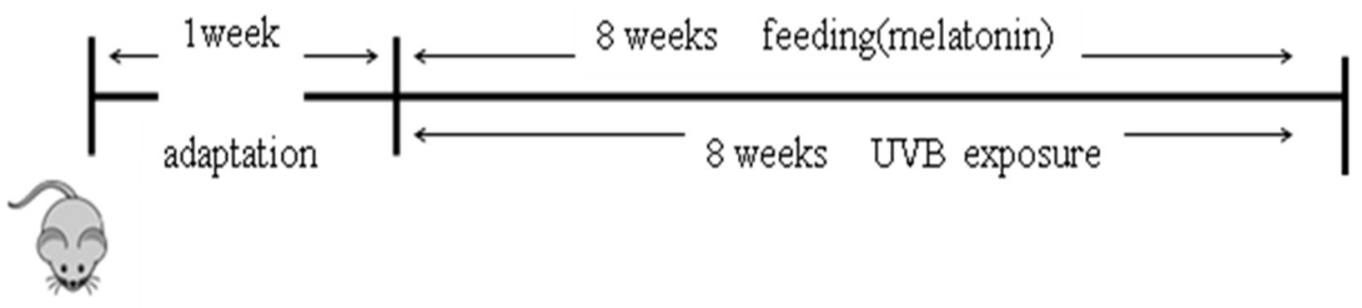

Figure 6. UVB irradiation schedule for SKH-1 hairless mice.

\subsection{Observation of Skin Wrinkle Formation}

The condition of skin wrinkle formation on the dorsal skin of hairless mice exposed to UVB irradiation was observed at 4 weeks and 8 weeks, the replicas were cast on the dorsal skin surface of the mice using SILFLO (Flexico developments LTD. Tokyo, Japan) and then photographed with a camera (Nikon D90, Tokyo, Japan).

\subsection{Measurement of Skin Moisture}

Mice were kept in the room in conditions of $21.5 \pm 2{ }^{\circ} \mathrm{C}$ and relative humidity of $40 \pm 5 \%$ for $30 \mathrm{~min}$. Skin moisture was measured in melatonin-treated mice using Corneometer CM 820 (Courage-Khazake, Koln, Germany).

\subsection{Histological Analysis}

The dorsal skin was obtained from the melatonin or retinoic acid treated group and control group mice by biopsy, fixed in $4 \%$ paraformaldehyde, dehydrated in ethanol and then embedded in paraffin. Approximately $10 \mu \mathrm{m}$-thick sections were deparaffinized and stained with hematoxylin-eosin (H\&E) and Masson's trichrome staining. Stained slides were then photographed using a light microscope (ZEISS ObserverAD2, Gottingen, Germany).

\subsection{Statistical Analysis}

For statistical analysis of the data, the Sigmaplot version 12 software (Systat Software Inc., San Jose, CA, USA) was used. All data were expressed as means \pm standard deviation (SD). A students $t$-test was used for the comparison of the two groups. The statistically significant differences were set at $p$ values of $<0.05$ between the control and melatonin/retinoic acid treated groups. 
Author Contributions: E.K.P. and H.-J.L. designed and performed several experiments. H.L., J.-H.K., J.H. and J.I.K. supported experiments. S.-H.K. supervised these experiments and wrote the manuscript.

Funding: This work is supported by the National Research Foundation of Korea (NRF) Grant funded by the Korea Government (MEST) (No. 2017R1A2A1A17069297).

Conflicts of Interest: The authors declare no conflict of interest.

$\begin{array}{ll}\text { Abbreviations } \\ \text { UVB } & \text { Ultraviolet B } \\ \text { t-BOOH } & \text { tert-Butyl hydroperoxide } \\ \text { ROS } & \text { Reactive Oxygen Species } \\ \text { MMP-1 } & \text { Matrix metalloprotease 1 } \\ \text { mRNA } & \text { messenger RNA } \\ \text { PCR } & \text { Polymerase Chain Reaction } \\ \text { SHH } & \text { Sonic hedgehog } \\ \text { p-ERK } & \text { Phospho-Extracellular Signal-regulated Kinase-1 } \\ \text { p-P38 } & \text { Phospho -P38 mitogen-activated protein kinases } \\ \text { COX-2 } & \text { Cyclooxygenase-2 } \\ \text { i.p } & \text { intraperitoneal } \\ \text { NF- } \text { KB } & \text { Nuclear factor kappa-light-chain-enhancer of activated B cells }\end{array}$

\section{References}

1. Hwang, K.A.; Yi, B.R.; Choi, K.C. Molecular mechanisms and in vivo mouse models of skin aging associated with dermal matrix alterations. Lab. Anim. Res. 2011, 27, 1-8. [CrossRef] [PubMed]

2. Fisher, G.J.; Kang, S.; Varani, J.; Bata-Csorgo, Z.; Wan, Y.; Datta, S.; Voorhees, J.J. Mechanisms of photoaging and chronological skin aging. Arch. Dermatol. 2002, 138, 1462-1470. [CrossRef] [PubMed]

3. Imokawa, G. Mechanism of UVB-induced wrinkling of the skin: Paracrine cytokine linkage between keratinocytes and fibroblasts leading to the stimulation of elastase. J. Investig. Dermatol. Symp. Proc. 2009, 14, 36-43. [CrossRef] [PubMed]

4. Imokawa, G.; Ishida, K. Biological mechanisms underlying the ultraviolet radiation-induced formation of skin wrinkling and sagging I: Reduced skin elasticity, highly associated with enhanced dermal elastase activity, triggers wrinkling and sagging. Int. J. Mol. Sci. 2015, 16, 7753-7775. [CrossRef] [PubMed]

5. Bossi, O.; Gartsbein, M.; Leitges, M.; Kuroki, T.; Grossman, S.; Tennenbaum, T. UV irradiation increases ROS production via PKCdelta signaling in primary murine fibroblasts. J. Cell. Biochem. 2008, 105, $194-207$. [CrossRef] [PubMed]

6. Avila Rodriguez, M.I.; Rodriguez Barroso, L.G.; Sanchez, M.L. Collagen: A review on its sources and potential cosmetic applications. J. Cosmet. Dermatol. 2018, 17, 20-26. [CrossRef] [PubMed]

7. Contet-Audonneau, J.L.; Jeanmaire, C.; Pauly, G. A histological study of human wrinkle structures: Comparison between sun-exposed areas of the face, with or without wrinkles and sun-protected areas. Br. J. Dermatol. 1999, 140, 1038-1047. [CrossRef] [PubMed]

8. Athar, M.; Tang, X.; Lee, J.L.; Kopelovich, L.; Kim, A.L. Hedgehog signalling in skin development and cancer. Exp. Dermatol. 2006, 15, 667-677. [CrossRef] [PubMed]

9. Li, C.; Chi, S.; Xie, J. Hedgehog signaling in skin cancers. Cell. Signal. 2011, 23, 1235-1243. [CrossRef] [PubMed]

10. Im, A.R.; Song, J.H.; Lee, M.Y.; Chae, S. Magnolol reduces UVB-induced photodamage by regulating matrix metalloproteinase activity. Environ. Toxicol. Pharmacol. 2015, 39, 417-423. [CrossRef] [PubMed]

11. Jeon, Y.; Jung, Y.; Youm, J.K.; Kang, K.S.; Kim, Y.K.; Kim, S.N. Abietic acid inhibits UVB-induced MMP-1 expression in human dermal fibroblast cells through PPARalpha/gamma dual activation. Exp. Dermatol. 2015, 24, 140-145. [CrossRef] [PubMed]

12. Sun, Z.W.; Hwang, E.; Lee, H.J.; Lee, T.Y.; Song, H.G.; Park, S.Y.; Shin, H.S.; Lee, D.G.; Yi, T.H. Effects of Galla chinensis extracts on UVB-irradiated MMP-1 production in hairless mice. J. Nat. Med. 2015, 69, $22-34$. [CrossRef] [PubMed] 
13. Roh, E.; Kim, J.E.; Kwon, J.Y.; Park, J.S.; Bode, A.M.; Dong, Z.; Lee, K.W. Molecular Mechanisms of Green Tea Polyphenols with Protective Effects against Skin Photoaging. Crit. Rev. Food Sci. Nutr. 2015, 57, 1631-1637. [CrossRef] [PubMed]

14. Cesquini, M.; Torsoni, M.A.; Stoppa, G.R.; Ogo, S.H. t-BOOH-induced oxidative damage in sickle red blood cells and the role of flavonoids. Biomed. Pharmacother. 2003, 57, 124-129. [CrossRef]

15. Wang, X.; Bi, Z.; Chu, W.; Wan, Y. IL-1 receptor antagonist attenuates MAP kinase/AP-1 activation and MMP1 expression in UVA-irradiated human fibroblasts induced by culture medium from UVB-irradiated human skin keratinocytes. Int. J. Mol. Med. 2005, 16, 1117-1124. [CrossRef] [PubMed]

16. Jiang, J.; Hu, C. Evodiamine: A novel anti-cancer alkaloid from Evodia rutaecarpa. Molecules 2009, 14, 1852-1859. [CrossRef] [PubMed]

17. Adachi, H.; Murakami, Y.; Tanaka, H.; Nakata, S. Increase of stratifin triggered by ultraviolet irradiation is possibly related to premature aging of human skin. Exp. Dermatol. 2014, 23, 32-36. [CrossRef] [PubMed]

18. Aggarwal, P.; Gera, J.; Ghosh, S.; Mandal, L.; Mandal, S. Noncanonical Decapentaplegic Signaling Activates Matrix Metalloproteinase 1 To Restrict Hedgehog Activity and Limit Ectopic Eye Differentiation in Drosophila. Genetics 2017, 207, 197-213. [CrossRef] [PubMed]

19. Oh, C.T.; Lee, D.; Koo, K.; Lee, J.; Yoon, H.S.; Choi, Y.M.; Kwon, T.R.; Kim, B.J. Superoxide dismutase 1 inhibits alpha-melanocyte stimulating hormone and ultraviolet B-induced melanogenesis in murine skin. Ann. Dermatol. 2014, 26, 681-687. [CrossRef] [PubMed]

20. Kim, J.H.; Duffy, J.F. Circadian Rhythm Sleep-Wake Disorders in Older Adults. Sleep Med. Clin. 2018, 13, 39-50. [CrossRef] [PubMed]

21. Leeboonngam, T.; Pramong, R.; Sae-Ung, K.; Govitrapong, P.; Phansuwan-Pujito, P. Neuroprotective effects of melatonin on amphetamine-induced dopaminergic fiber degeneration in the hippocampus of postnatal rats. J. Pineal Res. 2018, 64. [CrossRef] [PubMed]

22. Chen, Y.; Zhao, Q.; Sun, Y.; Jin, Y.; Zhang, J.; Wu, J. Melatonin induces anti-inflammatory effects via endoplasmic reticulum stress in RAW264.7 macrophages. Mol. Med. Rep. 2018, 17, 6122-6129. [CrossRef] [PubMed]

23. Nabavi, S.M.; Nabavi, S.F.; Sureda, A.; Xiao, J.; Dehpour, A.R.; Shirooie, S.; Silva, A.S.; Baldi, A.; Khan, H.; Daglia, M. Anti-inflammatory effects of Melatonin: A mechanistic review. Crit. Rev. Food Sci. Nutr. 2018, 1-62. [CrossRef] [PubMed]

24. Fischer, T.W.; Scholz, G.; Knoll, B.; Hipler, U.C.; Elsner, P. Melatonin reduces UV-induced reactive oxygen species in a dose-dependent manner in IL-3-stimulated leukocytes. J. Pineal Res. 2001, 31, 39-45. [CrossRef] [PubMed]

25. Bardak, Y.; Ozerturk, Y.; Ozguner, F.; Durmus, M.; Delibas, N. Effect of melatonin against oxidative stress in ultraviolet-B exposed rat lens. Curr. Eye Res. 2000, 20, 225-230. [CrossRef]

26. Fischer, T.W.; Zbytek, B.; Sayre, R.M.; Apostolov, E.O.; Basnakian, A.G.; Sweatman, T.W.; Wortsman, J.; Elsner, P.; Slominski, A. Melatonin increases survival of HaCaT keratinocytes by suppressing UV-induced apoptosis. J. Pineal Res. 2006, 40, 18-26. [CrossRef] [PubMed]

27. Baek, B.; Lee, S.H.; Kim, K.; Lim, H.W.; Lim, C.J. Ellagic acid plays a protective role against UV-B-induced oxidative stress by up-regulating antioxidant components in human dermal fibroblasts. Korean J. Physiol. Pharmacol. 2016, 20, 269-277. [CrossRef] [PubMed]

28. Liebel, F.; Kaur, S.; Ruvolo, E.; Kollias, N.; Southall, M.D. Irradiation of skin with visible light induces reactive oxygen species and matrix-degrading enzymes. J. Investig. Dermatol. 2012, 132, 1901-1907. [CrossRef] [PubMed]

29. Subedi, L.; Lee, T.H.; Wahedi, H.M.; Baek, S.H.; Kim, S.Y. Resveratrol-Enriched Rice Attenuates UVB-ROS-Induced Skin Aging via Downregulation of Inflammatory Cascades. Oxidative Med. Cell Longev. 2017, 2017, 8379539. [CrossRef] [PubMed]

30. Dlugosz, A.A.; Cheng, C.; Denning, M.F.; Dempsey, P.J.; Coffey, R.J.J.; Yuspa, S.H. Keratinocyte growth factor receptor ligands induce transforming growth factor alpha expression and activate the epidermal growth factor receptor signaling pathway in cultured epidermal keratinocytes. Cell Growth Differ. 1994, 5, 1283-1292. [PubMed]

31. Lewis, D.A.; Spandau, D.F. UVB-induced activation of NF-kappaB is regulated by the IGF-1R and dependent on p38 MAPK. J. Invest. Dermatol. 2008, 128, 1022-1029. [CrossRef] [PubMed] 
32. Khan, N.; Syed, D.N.; Pal, H.C.; Mukhtar, H.; Afaq, F. Pomegranate fruit extract inhibits UVB-induced inflammation and proliferation by modulating NF-kappaB and MAPK signaling pathways in mouse skin. Photochem. Photobiol. 2012, 88, 1126-1134. [CrossRef] [PubMed]

33. Lee, Y.R.; Noh, E.M.; Jeong, E.Y.; Yun, S.K.; Jeong, Y.J.; Kim, J.H.; Kwon, K.B.; Kim, B.S.; Lee, S.H.; Park, C.S.; et al. Cordycepin inhibits UVB-induced matrix metalloproteinase expression by suppressing the NF-kappaB pathway in human dermal fibroblasts. Exp. Mol. Med. 2009, 41, 548-554. [CrossRef] [PubMed]

34. Karthikeyan, R.; Kanimozhi, G.; Prasad, N.R.; Agilan, B.; Ganesan, M.; Mohana, S.; Srithar, G. 7-Hydroxycoumarin prevents UVB-induced activation of NF-kappaB and subsequent overexpression of matrix metalloproteinases and inflammatory markers in human dermal fibroblast cells. J. Photochem. Photobiol. B 2016, 161, 170-176. [CrossRef] [PubMed]

35. Jung, H.Y.; Shin, J.C.; Park, S.M.; Kim, N.R.; Kwak, W.; Choi, B.H. Pinus densiflora extract protects human skin fibroblasts against UVB-induced photoaging by inhibiting the expression of MMPs and increasing type I procollagen expression. Toxicol. Rep. 2014, 1, 658-666. [CrossRef] [PubMed]

36. Jung, H.; Lee, E.H.; Lee, T.H.; Cho, M.H. The Methoxyflavonoid Isosakuranetin Suppresses UV-B-Induced Matrix Metalloproteinase-1 Expression and Collagen Degradation Relevant for Skin Photoaging. Int. J. Mol. Sci. 2016, 17, 1449. [CrossRef] [PubMed]

37. Rimkus, T.K.; Carpenter, R.L.; Qasem, S.; Chan, M.; Lo, H.W. Targeting the Sonic Hedgehog Signaling Pathway: Review of Smoothened and GLI Inhibitors. Cancers 2016, 8, 22. [CrossRef] [PubMed]

38. Abe, Y.; Tanaka, N. Roles of the Hedgehog Signaling Pathway in Epidermal and Hair Follicle Development, Homeostasis and Cancer. J. Dev. Biol. 2017, 5, 12. [CrossRef] [PubMed]

39. Yaar, M.; Gilchrest, B.A. Photoageing: Mechanism, prevention and therapy. Br. J. Dermatol. 2007, 157, 874-887. [CrossRef] [PubMed]

40. Kim, H.S.; Song, J.H.; Youn, U.J.; Hyun, J.W.; Jeong, W.S.; Lee, M.Y.; Choi, H.J.; Lee, H.K.; Chae, S. Inhibition of UVB-induced wrinkle formation and MMP-9 expression by mangiferin isolated from Anemarrhena asphodeloides. Eur. J. Pharmacol. 2012, 689, 38-44. [CrossRef] [PubMed]

(C) 2018 by the authors. Licensee MDPI, Basel, Switzerland. This article is an open access article distributed under the terms and conditions of the Creative Commons Attribution (CC BY) license (http:/ / creativecommons.org/licenses/by/4.0/). 